\title{
A história dos estudantes "excedentes" nos anos 1960: a superlotação das universidades e um "torvelinho de situações improvisadas"
}

\section{The story of the 'surplus' students in 1960: overcrowding at universities and a "turmoil of improvised situations"}

\author{
Katya Mitsuko Zuquim Braghini ${ }^{1}$
}

\begin{abstract}
RESUMO
Analisar os discursos que registraram uma superlotação universitária acontecida no Brasil nos anos 1960, apresentando as dificuldades relacionadas à distribuição dos estudantes ao término do Ensino Médio é o objetivo deste artigo. Será dada ênfase à condição do aluno "excedente", jovens que passavam no vestibular, mas não conseguiam se matricular por falta de vagas, porque esse tema é reiteradamente tratado na bibliografia referente aos manifestos estudantis no período da ditadura militar brasileira. As fontes selecionadas para o estudo foram periódicos educacionais, legislação, pareceres, artigos de jornais diários e revistas semanais. Foi possível perceber que os estudantes ficaram à mercê de um entrave educacional na passagem entre os dois ciclos: no ensino médio havia um movimento que buscava acelerá-los para que o curso fosse concluído; no ensino superior, havia a barragem do fluxo, fosse por falta de vagas ou por outros transtornos de ordem social e acadêmica que serão discutidos no texto.
\end{abstract}

Palavras-chave: Ensino Superior; Ensino Médio; movimento estudantil; excedentes.

\begin{abstract}
To analyze the speeches that registered cases of overcrowding at universities in Brazil in the 1960s is the aim of this article, depicting the difficulties
\end{abstract}


related to the distribution of students leaving high school. Emphasis will be given to the condition of the "surplus" student: young people who passed the university entrance exam but could not enroll due to the lack of vacancies. This theme is repeatedly treated in literature regarding student manifestos during the Brazilian military dictatorship. The sources selected for the study were educational periodicals, legislation, opinions, articles of daily newspapers and weekly magazines. It could be observed that students were at the mercy of an educational barrier in passing from one cycle to the next. In high school, there was a movement that sought to speed them up so as to complete the course, while in higher education, the flow of students was dammed up either by the lack of vacancies or other social and academic disorders to be discussed in the text.

Keywords: higher education; secondary education; student movement; surplus.

\section{Introdução}

No texto "O espectro da Revolução" o historiador inglês Tony Judt (2007) fez uma análise sobre a juventude universitária europeia nos anos 1960. De acordo com o pesquisador, aquela geração não só via o mundo novo, como todas as outras gerações passadas: Ela via um mundo novo e jovem. Os jovens estavam em todos os lugares (JUDT, 2007, p. 48).

A maioria dos europeus, até a década de 1960, nunca tinha entrado numa escola secundária. Ainda que a maioria dos jovens europeus não fossem estudantes, nos anos 1960 aconteceu uma superlotação das universidades, fenômeno social que demonstrou o despreparo geral dessas instituições para receber o contingente de jovens que buscavam o ensino superior (JUDT, 2007, p. 50).

Nas universidades, ao final da década de 1960, "tudo vivia lotado": salas de aula, bibliotecas, refeitórios, dormitórios etc., e a "qualidade da experiência acadêmica" não acompanhava o ritmo da demanda estudantil. O pesquisador demonstrou que, numa época de crescimento econômico e prosperidade, o maior problema enfrentado pelos dirigentes na Europa "não era como alimentar, vestir, dar moradia ou empregar o número crescente de jovens, mas como educá-los" (JUDT, 2007, p. 48).

$\mathrm{Na}$ França, o contingente de jovens entre 16 e 24 anos chegava a 8 milhões de pessoas, o que significava $16 \%$ da população. Nesse mesmo país, em 1950, havia 32 mil bacheliers, os formados no ensino médio, enquanto que em 1970 eles representavam $20 \%$ dos jovens. Também nos anos 1950, na Alemanha 
Ocidental havia 108 mil estudantes nas universidades. No final dos anos 1960 esse número tinha saltado para 400 mil. No caso da Itália, tanto o sistema de cotas fixas, quanto o vestibular foram abolidos e a entrada na universidade foi tornado um direito. Nos anos 1950, um em cada vinte estudantes italianos estava na universidade. Vinte anos depois a proporção era de um a cada sete estudantes (JUDT, 2007, p. 49-50).

Em outras palavras, o crescimento demográfico juvenil impactou o sistema de ensino europeu, mas, além disso, se antes a universidade estava aparelhada para formar um grupo restrito de pessoas, nesse período essa instituição passou a conviver com a ideia de formar grandes públicos.

Essa nova realidade nos faz pensar sobre os movimentos sociais, políticos e educacionais que foram necessários para a adequação do ensino superior no movimento de formação em massa. Esse artigo não pretende ser um estudo comparado, mas entende que a irrupção abrupta de jovens nas universidades foi um fenômeno social percebido no mundo todo, inclusive no extremo oriente, apontando que a entrada de um grande número de estudantes no ensino superior não foi um caso isolado no Brasil. Aqui, passamos a tratar das especificidades brasileiras.

No Brasil no final dos anos 1960 foi possível detectar a questão da superlotação universitária como um fenômeno escolar, a partir da história dos "excedentes". Excedentes eram os candidatos que obtinham a média nos vestibulares, mas não conseguiam se matricular nas escolas de nível superior, pois o número de aprovados extrapolava ao número de vagas disponíveis. Não raro, nos anos 1960, as manifestações juvenis tocavam nesse assunto e parte das reivindicações estudantis daquele período estava diretamente relacionada a esse "ponto de estrangulamento" na trajetória escolar dos estudantes brasileiros: havia jovens buscando o ensino superior, eles atingiam as médias pedidas nos vestibulares e, ao final, por conta da insuficiência de postos universitários, não assumiam a vaga requerida.

A questão dos "excedentes", portanto, pode ser compreendida como um ponto importante dentro do que era apontado como "crise educacional" que se estendeu ao longo da década de 1960 e que foi disparadora de uma série de movimentos estudantis universitários de contestação. Ponto histórico destacado, porque revelou uma deficiência na articulação do ensino superior em relação ao ensino médio (CUNHA, 2007, p. 83; FÁVERO, 2006, p. 32; MATHIAS, 2004, p. 166; VALLE, 1999, p. 38; FORACCHI, 1972, p. 152).

Os problemas relacionados à trajetória educacional dos jovens e aos critérios de passagem ao mundo adulto amplificaram as vozes estudantis contrárias à ditadura militar, demarcando-as na história. Os jovens anunciavam um entrave no fluxo escolar brasileiro apresentando-o como um obstáculo na trajetória para 
a vida adulta; uma demanda social que aguardava uma atuação do Governo; um problema que estava diretamente vinculado ao fechamento das liberdades civis, já que manifestações dessa categoria, voltadas à melhoria da educação em geral, acabaram relacionadas à subversão da ordem.

Analisar as diferentes camadas de interesses nos discursos que perceberam a superlotação universitária, apresentando as dificuldades, de várias ordens, relacionadas à distribuição dos estudantes ao término do Ensino Médio é o objetivo deste artigo. Nos anos 1960 tanto as explicações para o fenômeno dos excedentes, quanto a busca de soluções para o problema foram tornadas pautas de debates em várias instâncias, o que nos mostra o caráter multifacetado do obstáculo em questão, capaz de gerar debates em torno do funcionamento do ensino superior, posicionamentos em torno de uma grande reforma universitária, a distribuição de fundos para os diversos níveis de ensino, o significado dos vestibulares etc.

Para esse estudo foram investigados os discursos proferidos em diferentes veículos de comunicação - periódico educacional, jornais diários, revistas semanais -, bem como a ordenação jurídica pertinente ao tema - pareceres, relatórios de comissões, leis e decretos. Primordialmente foram analisados os documentos produzidos pela Editora do Brasil, principalmente a revista educacional por ela produzida, a Revista da Editora do Brasil S/A (EBSA), por conta do seu caráter conservador diante das manifestações estudantis contrárias ao fechamento das liberdades civis (BRAGHINI, 2010)2.

\section{A entrada de estudantes no ensino superior brasileiro nos anos 1960}

A Revista da Editora do Brasil S/A (EBSA) dizia que as manifestações estudantis eram sintoma daquilo que a própria Revista chamou de "torvelinho de experiências improvisadas" durante a passagem do Ensino Médio para o Ensino Superior brasileiro (GOMES, 1968, p. 2). Situações "improvisadas" definiam as condições de entrada dos jovens na universidade brasileira naque-

2 Esse artigo é um resultado parcial da tese A "vanguarda brasileira": a juventude nos discursos da Revista da Editora do Brasil S/A (1961-1980). A tese apresenta a imagem que foi construída sobre a juventude nos anos 1960 e 1970 a partir, principalmente, de documentos produzidos por essa editora ou citado e republicado por ela. Os editores, por se apresentarem notadamente favoráveis à ditadura militar, podem ser considerados como uma espécie de "contraface" de uma parcela dos jovens que se manifestavam durante o período da ditadura militar. Foi levado em consideração que diante dos manifestos juvenis um "projeto de juventude" foi organizado pelos editores, possivelmente buscando um ideal de jovem que fosse mais conveniente ao regime instituído pelo golpe militar. 
le período: às vezes conseguiam a vaga, mas não conseguiam se matricular. Caso conseguissem se inscrever, encontravam uma universidade lotada, muito comum, desaparelhada e, às vezes, com discursos contrários à "massificação" do meio acadêmico.

Vale dizer que a questão dos "excedentes" não era matéria nova nos anos 1960, já que a Lei 1.392, de 11 de julho de 1951, estabelecia exatamente as normas para o aproveitamento de "excedentes" em escolas particulares. Essa lei, assinada pelo então Presidente Getúlio Vargas, pedia pelo aproveitamento dos alunos aprovados e não classificados nas escolas superiores públicas pelos cursos das escolas privadas, levando em conta a capacidade das instalações e a possibilidade de atendimento de seu corpo docente.

Se em 1960, 29 mil estudantes prestaram os vestibulares e não conseguiram vagas nas instituições para as quais tinham sido aprovados, esse número aumentou consideravelmente em 1969, com 162 mil estudantes perdendo as vagas. O Jornal do Commercio registrou que havia mais excedentes de vestibulares, em 1963, "do que em todos os anos anteriores"3. Em 1968, o número de vagas no ensino superior era cinco vezes inferior ao número de candidatos que as disputavam. No início dos anos 1960, de acordo com os dados apresentados na tabela abaixo, houve aumento tanto no número de matrículas das instituições públicas, quanto nas escolas privadas, estas com menor procura.

TABELA 1 - NÚMERO TOTAL DE MATRÍCULAS NO ENSINO SUPERIOR, ESCOLAS FEDERAIS, ESTADUAIS, MUNICIPAIS (1956 E 1960)

\begin{tabular}{|c|c|c|c|}
\hline \multirow{2}{*}{ Anos } & \multirow{2}{*}{ Total de Matrículas } & \multicolumn{2}{|c|}{ Instituições } \\
\cline { 3 - 4 } & 78.659 & Públicas & Privadas \\
\hline 1956 & 95.691 & 50.297 & 38.362 \\
\hline 1960 & 21,65 & 33,024 & 42.067 \\
\hline $\begin{array}{c}\text { \% de crescimento entre } \\
1956-1960\end{array}$ & 9,66 \\
\hline
\end{tabular}

FONTE: Sinopse Estatística do Ensino Superior. Ministério da Educação e Cultura, 1965. p. 6-7.

A explicação corrente, dada pela historiografia, diz que esse crescimento populacional universitário foi ocasionado pelo aumento do número de jovens que deram sequência nos estudos após o término do ensino médio, a partir de um super dimensionamento do número de adolescentes no Ocidente. Esse fenômeno demográfico, acontecido após a Segunda Guerra Mundial, foi demarcado na história norte-americana como baby boom. 
No caso do Brasil, a questão da multidão de estudantes às portas do ensino superior também esteve relacionado ao fluxo de alunos saídos do ensino médio, principalmente a partir de um dos seus segmentos, o ensino secundário, que também carecia de vagas, e cuja taxa de matrícula havia crescido 4,3 pontos entre 1947 e 1964. No caso das discussões em torno do ensino médio, houve tanto o estímulo para que os alunos não obstruíssem o fluxo da seriação dos cursos, evitando-se as reprovações, quanto a possibilidade de que todos os estudantes desse nível de ensino pudessem prestar o vestibular após a instituição das Leis de Equivalência.

A ideia de desobstruir a passagem no ensino médio e a aceleração de estudantes para que não ficassem retidos e terminassem o curso rapidamente, ficou transparente nas reações, tanto a favor como contrárias, ao ato de Gildásio Amado, da Diretoria do Ensino Secundário, em 1963. Tratava-se da chance dada aos alunos de prestar exames de segunda época em até quatro disciplinas, a fim de evitar as reprovações de final ano. De um lado, o Jornal do Commercio dizia que a "necessidade de facilitar o ensino" significava rebaixar os padrões de estudo 4 . Já para o Diário de Notícias, conceder a chance para que os estudantes pudessem fazer exames de segunda época era "perfeitamente justo e normal", pois a "perda de um ano letivo", segundo o autor, repercutia "consideravelmente em todos os orçamentos" (EBSA, 1963, p. 49-51).

A discussão sobre a aceleração ou não de alunos ao término do ensino médio tem a sua importância mediante o fato de existir, desde 1950, a possibilidade de que todos os seus alunos prestassem o vestibular a partir do que foi determinado pelas "leis de equivalência". As chamadas Leis de Equivalência, respectivamente, de $\mathrm{n}^{\circ} 1.076(1950), \mathrm{n}^{\circ} 1.821$ (1953), e $\mathrm{n}^{\mathrm{o}} 3.104$ (1957) foram, paulatinamente, dando condições para que os egressos dos diversos ramos do ensino médio, formação militar ou sacerdotal, pudessem, sob o cumprimento de uma série de balizas educacionais, prestar o vestibular. Foi a Lei de Diretrizes e Bases da Educação Nacional (Lei no 4.024, de 20 de dezembro de 1961), em seu artigo 79 , que estabeleceu, definitivamente, a equidade dos alunos dos diferentes cursos de nível médio, ao determinar que todos os seus concluintes tivessem acesso ao vestibular, sem a necessidade de complementação de matérias. Essa decisão, ao mesmo tempo em que alargava o caminho para um maior número de alunos rumo à próxima etapa, pode ser considerada o término "oficial" de uma condição histórica que elitizava o aluno do ensino secundário, já que somente ele, entre 1942 até 1961, podia pleitear, livremente, uma cadeira na universidade 5 .

4 Transcritos do Jornal do Commercio, Rio de Janeiro, 18/04/1963 e do Diário de Notícias, Rio de Janeiro, 04/02/1963.

5 A Lei Orgânica do Ensino Secundário (Decreto-Lei nº 4.244/1942) dizia que ensino secundário deveria ser o único "corredor" de passagem para o ensino superior. O ensino médio 
Outro assunto, ainda mais polêmico, apontava para a falta de vagas, principalmente no ensino secundário, e jogava luz sobre o dispositivo Lacerda, que pedia a concessão de bolsas de estudo pagas pelo dinheiro público, mas voltadas ao ensino privado. A despeito de o ensino privado ser beneficiado por dinheiro público, nesses discursos soava "bem intencionado" o custeio "parcial" dos estudos de nível médio, nas escolas particulares, de modo que fosse aumentado o número de vagas. De acordo com os cálculos apresentados, "elevaram-se a mais de 50 mil as oportunidades oferecidas pelo Estado, de matrículas nas escolas de ensino médio" (EBSA, 1963 p. 36). ${ }^{6}$ A discussão sobre o escoamento de patrimônio público para o fortalecimento da escola privada era calorosa e conhecida pela historiografia da educação, e a ideia de aumento de vagas passou a ser uma das principais alegações para a concessão de vantagens financeiras ao universo privado. Entretanto, a possibilidade de subsídio dado à parcela privada da Educação, em 1964, parece ter motivado os debates em torno do corte de verbas para o incremento das universidades públicas sob as quais incidia a pressão dos excedentes (CUNHA, 2007, p. 83-84).

Aparentemente, os dois segmentos de ensino não conseguiam lidar com a concentração de jovens na articulação entre eles, fosse pelo caminho privado ou pelo público. No caso dos textos publicados pela EBSA havia uma associação direta entre os problemas do ensino superior com outros níveis de ensino. Segundo esse periódico, grandes quantias eram lançadas nas Universidades dando privilégio a uma elite intelectual (alunos e professores), enquanto outras frações de ensino ficavam à mercê da falta de dinheiro. Essa tensão, à época, ainda era reforçada pelo jargão: "O governo gasta pouco com a Educação", e "como emprega mal o pouco que gasta" (EBSA, 1962, p. 1).

De todo modo, os dados diziam que, de um grupo de 1000 estudantes, entre 12 e 18 anos, 11,5 concluíram a $4^{\circ}$ série do nível médio; 5,5 concluíram a $7^{\text {a }}$ série do mesmo nível e apenas 2,29 alcançaram o nível superior de educação (REALIDADE, 1967, p.23). Mesmo diante da possibilidade legal de entrada no ensino superior, percebeu-se que muitos alunos eram reprovados ao longo do fluxo escolar. A ideia de aceleração dos estudantes ao longo da seriação foi tornada válida e poucas eram as vagas disponíveis para a próxima etapa escolar.

brasileiro possuía os níveis ginasial (4 anos) e colegial ( 3 anos), divididos nos seguintes cursos: ensino secundário, ensino industrial, ensino comercial, ensino rural e ensino normal, cada um deles regido por legislação particular.

6 Essa condição estava prevista nas alíneas "a" e "b" do artigo 94 da Lei de Diretrizes e Bases da Educação - Lei n ${ }^{\circ}$ 4.024/1961.

7 Dados do Censo de 1960 apontavam as verbas destinadas para o ensino: Ensino Primário: 5.905.000.000,00 (12\%); Ensino Médio: 7.178.000.000,00 (15\%); Ensino Superior: $36.419 .000 .000,00(73 \%)$. 
No caso da Universidade, em 1967, havia 160 mil jovens matriculados, e esse montante representaria menos de $2 \%$ da população entre 19 e 25 anos $^{8}$. Como veremos a seguir, mesmo com menos de $2 \%$ dos jovens dentro da Universidade, a sua continuidade dos estudos não seria facilitada, nem havia a garantia de que ela se concretizaria.

A questão da distribuição das finanças também recaía sobre o universo universitário, já que a falta de espaço estimulava a discussão sobre a ampliação das instituições e a distribuição federativa dos cursos. Nos anos 1960 a quantia acumulada para a ampliação das universidades parecia insuficiente e o dinheiro orçado para a Educação era distribuído, segundo o parecer do então Ministro da Educação, de forma desequilibrada. Flávio Suplicy de Lacerda, em 1964, reclamava sobre uma grande despesa da União com a federalização de escolas e universidades e dizia que o dinheiro seria escasso para amenizar os problemas em curso (EBSA, 1962, p. 45).

O Grupo de Trabalho da Reforma Universitária (GT), em 1967, tinha em mente a ideia de "expansão com contenção" e foi guiado pela recomendação de planejamento organizado dos recursos humanos e materiais dentro das universidades ${ }^{9}$. Mesmo diante do discurso da escassez e de contenção de recursos, parece ter havido um modelo de fomento que produziu efeito em algumas instituições, no sentido de se buscar a ampliação dos espaços destinados à produção científica e tecnológica e a formação de quadros de trabalho qualificados dentro de um plano de melhoria concentrada em escolas superiores públicas e confessionais (MARTINS, 2009, p. 16). O Banco Nacional de Desenvolvimento Econômico (BNDE) e, posteriormente, a Financiadora de Estudos e Projetos (FINEP) passaram a fornecer auxílios financeiros às instituições publicas, por meio do Fundo de Desenvolvimento Técnico-Científico, criado em 1964, possibilitando às universidades federais a construção de novas instalações, a construção de laboratórios, a institucionalização da carreira docente etc. (MARTINS, 2009, p. 21).

No entanto, estruturava-se, nessa mesma ocasião, um modelo duplamente seletivo de universidade federal:

no plano social, suas vagas passariam a ser ocupadas por um grupo restrito de estudantes dotados de razoável volume de capital econômico e/ou cultural; no plano acadêmico, procurava-se concretizar um elevado

8 Em 1967, quase dois terços da população brasileira tinham menos de 25 anos. Desses, cerca de 15 milhões estavam entre os 15 e 25 anos (Realidade, 1967, $\mathrm{n}^{\circ} 18$ ).

9 O grupo de trabalho para a discussão sobre a reforma Universitária foi instituído pelo Decreto $n^{\circ} 62.937$, de 2 de julho de 1968. 
padrão de qualidade acadêmica, fundado na associação entre ensino e pesquisa, no interior do qual a pós-graduação exerceria um papel central. A motivação subjacente a esse modelo era preservar as universidades federais de um eventual processo de massificação (MARTINS, 2009, p. 21-22).

De acordo com o pesquisador houve, por um lado, a seleção inicial de estudantes que acontecia por conta de seu próprio histórico cultural e econômico. Posteriormente, o processo seletivo aconteceria ao longo da constituição da carreira discente, já que o ensino superior, internamente, fazia uma triagem, selecionando e classificando os grupos, evitando, assim, o processo de popularização.

O processo de seleção universitária interessada na continuidade de formação de uma elite intelectual estudantil também foi descrito por Bourdieu e Passeron na obra Os Herdeiros (1964). Os dois estudiosos analisaram estatísticas, estudaram as regras universitárias, se apoiaram em um estudo empírico do comportamento de professores e estudantes e tornaram evidentes os processos sociais e a filtragem educacional que mantinham os elementos de uma elite intelectual como uma categoria social proprietária de vagas nas Grandes Escolas da França. O estudo percebeu tanto os procedimentos "invisíveis" mantidos pelas instituições superiores para a seleção e manutenção de seus quadros escolares, quanto o poder do histórico intelectual dos jovens, advindo como herança familiar, no momento de pensar a Universidade como caminho "natural" na trajetória de vida (BOURDIEU; PASSERON, 1964, p. 12).

Outro exemplo dessa alteração do quadro social selecionador de pessoas às portas do ensino superior foi dado pelo professor, editor e escritor Alfredo Gomes. Segundo o editor, o fenômeno social selecionador que tinha nas escolas superiores o seu ápice tinha enfraquecido. A ascensão social no Brasil estava "menos organizada" e o "equilíbrio das elites dirigentes" havia se "rompido", pois estar na universidade não mais demarcaria a existência de uma elite condutora (GOMES, 1968, p. 2). Tinha-se a ideia de que as "novas camadas sociais" eram preparadas "mais extensivamente e menos intensivamente" e que a própria universidade teria inventado uma nova forma de seleção social: feita durante o processo de formação dos alunos, dentro dos moldes da meritocracia. Esse novo método de seleção resultava no aparecimento de "gênios", alunos destacados que, pelo "espírito da emulação", eram sobressaltados diante da massificação em curso.

Barrar os estudantes, responsabilizando-os pela massificação da Universidade, foi uma tendência percebida também pelo jornalista do Jornal do 
Brasil, Carlos Flexa Ribeiro, em março de 1967. Anunciando uma "educação em falência", de modo a reforçar uma crise política, o jornalista refletiu sobre o prolongamento de "pontos clássicos de estrangulamento" no sistema de ensino do Brasil, que ficaram mais aparentes à medida que a procura pelos três níveis de ensino aumentou, e a escola tornou-se uma "aspiração generalizada"10. Para o autor os responsáveis pela existência desses pontos de estrangulamento eram: a) os políticos, que faziam uso do "tráfico político dos recursos da educação, para fins eleitorais e de carreira"; b) a classe média e alta que exigia dos filhos o título de doutor; c) o magistério oficial de ensino superior, "na sua parte menos disposta às mudanças"; d) a parcela dos estudantes "profissionais" que usavam as vagas para fins políticos enquanto outros poderiam usar a vaga para estudar; e) a imprensa de "oposição" que protegia o regime de educação por "superproteção", modo como a classe média abastada educava os seus filhos (RIBEIRO, 1967).

Dantas (1997), por exemplo, nos conta o caso da Universidade de São Paulo (USP), que buscou impedir a entrada de alunos despreparados por conta das "deficiências do ensino secundário". De acordo com a pesquisadora, como o Governo não resolveria, em curto prazo, essas "deficiências", caberia às universidades definir esquemas "compensatórios" para proteger seus cursos e instituições e, com isso, manter o status de local do saber (DANTAS, 1997, p. 27).

A possibilidade de seleção social e a organização de formas de contenção do povo na universidade pública brasileira não pareceram ideias distantes sob o ponto de vista da própria Universidade. O reitor licenciado da Universidade Federal do Rio Grande do Sul, prof. Eliseu Paglioli, tentou explicar o gasto com a federalização do ensino superior brasileiro em um Fórum de Reitores, em Curitiba, jogando o foco para o inchaço de alunos, chamando-o de "inflação universitária", e para os professores das universidades federais que não abririam mão de seu status em benefício da Educação, dando a entender que havia um processo de fechamento vindo de dentro da universidade.

Segundo o discurso do professor, a "inflação" de alunos teria sido o motivo da abertura de estabelecimentos isolados e privados de ensino superior, estes que, por sua vez, alavancavam, logo que podiam, o "pedido de federalização" com vista à sua manutenção pelos cofres públicos (EBSA, 1963, p. 36). De acordo com o professor Paglioli, o volume de alunos às portas da Universidade evidenciava que os professores universitários, catedráticos, não abririam mão nem da posição social adquirida, nem dos recursos financeiros, pensando no benefício de outros ramos de ensino (EBSA, 1963, p. 36).

Da parte do Reitor, surgiu a ideia de bloquear a passagem de alunos que inflacionavam o ensino público. Por outro lado, havia tanto a reclamação sobre

10 Jornal do Brasil, Rio de Janeiro, 5 e 6 de março de 1967 - Caderno Especial, p. 2. 
a abertura de escolas isoladas que dispersava o financiamento existente para a ampliação dos serviços públicos, quanto o protesto contrário ao movimento de "federalização" de escolas que não se mantinham diante da pressão da lotação. Além disso, o professor partiu em defesa do ensino superior, jogando ênfase na educação de nível médio.

A respeito de uma suposta impossibilidade de o ensino superior comportar os seus pleiteantes foi aventada a possibilidade de distribuí-los pelos diversos ramos do nível médio, para que o volume de interessados em dar sequência vertical à carreira fosse amenizado. O ensino médio profissionalizante deveria ser, segundo esses discursos, uma bandeira de luta e, em meados da década de 1960, passou-se à defesa da distribuição de alunos por esse tipo de ensino, entendido como "ensino terminal". As aptidões dos alunos seriam desenvolvidas na escola, dessa forma eles poderiam assumir, imediatamente, uma posição profissional, e não necessariamente, procurariam o curso superior ${ }^{11}$. Além disso, essa ideia tinha interesse de suavizar a carga de prestígio do ensino secundário que, socialmente, ainda perdurava no imaginário, pois ainda mantinha-se a égide de ensino formador de uma elite intelectual e dirigente.

O "projeto de articulação entre o ensino médio e superior" do conselheiro Valnir Chagas pautou a reunião extraordinária do Conselho Federal de Educação (CFE) de 13 de dezembro de 1967 e buscava soluções para a questão dos alunos excedentes. Para o redator os problemas da falta de articulação entre os dois níveis de ensino eram de planejamento, estatística, orçamentos, de medidas político-administrativas. O Conselho, diante da expectativa de que haveria mais ingressantes em universidades no ano seguinte, fez a apreciação do projeto tendo em mente uma nova forma de distribuição de pessoas pelos ramos de ensino existentes (CHAGAS, 1968, p. 247).

Segundo a avaliação do CFE, mediante a expansão das matrículas, era necessário pensar na "criação de novas carreiras profissionais e mudança estrutural na sistemática atual com ginásios voltados às formas de trabalho e dois ciclos universitários". O sentido de transição entre o ensino médio e o ensino superior deveria ser "tanto mais simples e natural". Caso o sentido do ensino médio fosse de terminalidade, a transposição social era imediatamente voltada ao trabalho. Já o ensino superior poderia ser reordenado em dois ciclos: o primeiro, de cursos técnicos, para os alunos egressos do ensino médio que não "revelassem o pendor para os estudos longos, de três os mais anos letivos"; o segundo, "para quem continuasse nas carreiras" (CHAGAS, 1968, p. 260-265).

Diante de novas reivindicações do movimento estudantil, inclusive pedindo vagas, vemos em 1968 a instalação de duas comissões que, de forma diferente

11 Transcrito do Jornal do Commercio, Rio de Janeiro, 10/07/1964. 
e complementar, discutiram a questão dos excedentes dentro de um conjunto ampliado de problemas relacionados à universidade brasileira: a Comissão Meira Mattos e o Grupo de Trabalho da Reforma Universitária.

No caso do curso superior, no Grupo de Trabalho instituído para a discussão sobre a Reforma Universitária, havia um aparente contragosto pela entrada de um contingente humano que desfavorecia o ensino de "alta cultura", mas não havia como se abster do crescente fluxo de candidatos, o que motivava os debates em torno de soluções sobre a abertura dos cursos superiores, principalmente os federais, à "legião" de jovens às suas portas. A ideia principal era a criação de instrumentos de absorção dos grupos e uma das saídas, já apresentadas, consistia exatamente na divisão dos cursos de graduação em dois ciclos, um "básico" e outro "profissional". No caso, o ciclo básico era apresentado como uma espécie de estágio que visava abrandar as possíveis falhas de conteúdo dado no ensino médio e um local de reorientação da carreira que seria formalizada no ciclo subsequente. Havia também a possibilidade de oferecimento de cursos com o tempo mais reduzido que deveriam abastecer as áreas profissionais mais ajustadas "às modernas exigências de trabalho"'.

A ideia de curso de curta duração foi contemplada na Reforma Universitária pela Lei $n^{0} 5.540$ de 28 de novembro de 1968, no seu artigo 23, que dava autonomia aos estabelecimentos superiores no sentido de flexibilizar os seus cursos em diferentes modalidades quanto ao número, duração e condições locais do mercado de trabalho ${ }^{13}$. Além disso, os parágrafos $1^{\circ}$ e $2^{\circ}$ lançaram as possibilidades de cursos de curta duração levando em conta as "habilitações intermediárias" de grau superior e aproveitamento de estudos dos ciclos básicos e profissionais no caso de seguimento de carreira.

12 Segundo Cunha (2007, p. 220), eram os membros do Grupo de Trabalho: Tarso Dutra, deputado federal (RS) e Ministro da Educação, presidente do GT; Antônio Moureira Couceiro, professor na UFRJ e presidente do Conselho Nacional de Pesquisas; padre Fernando Bastos D’Ávila, vice-reitor da PUC-RJ e assessor da Associação dos Dirigentes Cristãos de Empresas; João Lyra Filho, reitor da Universidade Federal do Estado da Guanabara; João Paulo dos Reis Velloso, representante do Ministro do Planejamento; Fernando Ribeiro do Val, representante do Ministro da Fazenda; Roque Spencer Maciel de Barros, catedrático da Universidade de São Paulo, membro e relator da Comissão de reestruturação da USP; Newton Sucupira, ex-professor, ex-diretor e ex-Reitor da Universidade Federal de Pernambuco, membro do Conselho Federal de Educação; Valnir Chagas, ex-professor e ex-diretor de faculdade na Universidade Federal do Ceará, membro do Conselho Federal de Educação; João Carlos Moreira Bessa, presidente do Diretório Central dos estudantes da PUC-RJ e Paulo Rosas, aluno da Escola de Engenharia da UFRJ. Os dois alunos foram indicados pelo Movimento Universitário para o Desenvolvimento Econômico e Social (MUDES), entidade criada por empresários para a promoção de estágio de estudantes, entre outras finalidades.

13 Lei $\mathrm{n}^{\circ} 5.540$ de 28 de novembro de 1968 . Fixa normas de organização e funcionamento do ensino superior e sua articulação com a escola média, e dá outras providências. 
A Câmara de Planejamento do Conselho Federal de Educação acreditava que não havia a necessidade de abertura de novas escolas, mas era necessário um replanejamento sobre as capacidades das escolas já existentes. De certo modo, evitava-se explorar a abertura de novas escolas superiores, já que isto acabaria ampliando a distribuição dos recursos, diminuindo o repasse para as instituições que estavam em funcionamento. Mas o grupo não descartava a concessão financeira às universidades privadas para a ampliação de seus quadros e serviços, caso elas provassem ter um ensino de alto padrão e estar em compasso com a Política Nacional de Desenvolvimento ${ }^{14}$.

De acordo com os dados levantados por Trigueiro (1967) em 1965, havia 30 universidades em funcionamento. Dentre elas, existiam oito universidades com menos de 1.000 alunos; sete entre 1.000 e 1.500 ; cinco entre 1.500 e 2.000; três entre 2.000 e 3.000; apenas cinco escolas superiores contavam com mais de 5.000 matrículas e, por fim, somente duas possuíam mais de 10 mil alunos. Já segundo os dados recolhidos por Freitag (1986, p. 112), no ano de 1968, havia 278.295 estudantes matriculados; em 1973, o número saltou para 836.469, o que acarretou em um aumento de $300 \%$ no número de matrículas. Após a Reforma Universitária, foi percebida a aceleração na abertura de escolas isoladas particulares, pois se em 1968, no ensino público existiam 153.199 matriculados, para 124.496 na rede privada; em 1973, nas escolas oficiais estudavam 327.352, enquanto que nas privadas, 309.117. Segundo o apontamento, o ensino superior privado cresceu $410 \%$ contra $210 \%$ do ensino público.

Entretanto, a reforma universitária não conseguiu alcançar o duplo objetivo de frear a corrida à universidade e de ampliar de tal forma o número de vagas que correspondesse aproximadamente à procura. De acordo com Trigueiro (1967, p. 164) havia um número considerável de universidades para o período, mas quase todas tinham pequena capacidade e logo atingiam o seu nível de saturação. Esse analista percebia que o Ministério da Educação não tinha uma forma objetiva de medir a real capacidade das escolas superiores; não havia exato controle sobre as causas do estrangulamento e o órgão federal ainda aceitava a recusa das instituições em modificar as suas estruturas no esforço para manter o seu status. Por esses motivos, segundo o professor, novas escolas, também deficientes, eram abertas como um sistema de "válvulas de escape", mas que não conseguiam dar fim ao problema da falta de vagas.

Dentro do Conselho Federal de Educação, os pedidos feitos por escolas superiores para aumentar o número de vagas e de matrículas de excedentes

14 Parecer 209/1967 da Câmara de Planejamento do Conselho Federal de Educação (CEF). Assinam: Clóvis Salgado, Anísio Teixeira, Raymundo Moniz de Aragão, Edson Franco e o Padre José de Vasconcellos. 
eram uma rotina e os conselheiros tinham que estudá-los caso a caso, pois os requerimentos eram diferentes e as circunstâncias locais, materiais, objetivas, forçavam uma fiscalização mais atenta, o que, por vezes, inviabilizava o pedido. No caso da Faculdade de Direito de Guarulhos, por exemplo, foi pedida a matrícula de 185 excedentes. Mas o perito destacado para a diligência registrou que, mesmo as novas salas construídas, um total de 17, não seriam suficientes para acomodar todos os alunos quando as cinco séries estivessem em pleno funcionamento (Parecer n $\mathrm{n}^{\circ} 343$ de 6/07/1968). Mais tarde, no entanto, em outubro do mesmo ano, a mesma Faculdade retornou com o pedido de matrícula dos 185 excedentes para o bacharelado na $1^{\text {a }}$ série, em uma classe onde já se encontravam 200 estudantes. Segundo o documento, a tendência do Conselho seria o de negar o pedido. No entanto, os tais alunos já tinham sido admitidos condicionalmente e o espaço comportou a todos, o que acabou resultando em uma aprovação de matrícula de excedentes em caráter excepcional (Parecer $\mathrm{n}^{\circ}$ 613 de 7/10/1968).

O caso da Faculdade de Medicina de Itajubá foi bastante diferente. Essa instituição ampliou suas instalações e enriqueceu o seu equipamento para abarcar mais 100 alunos e recebeu imediata aprovação do processo (Parecer $\mathrm{n}^{\circ}$ 364 de 6/07/1968). Já o processo da Faculdade de Direito do Distrito Federal demonstrou outros limites para o balizamento dos pedidos. No caso, a instalação da faculdade tinha a capacidade de receber 200 ou mais alunos. Entretanto, segundo o parecer, o estabelecimento não planejou a "elasticidade do pessoal administrativo e a tolerância do corpo docente" que também seriam afetadas com o aumento de alunos, fato que, neste episódio, impediu a aprovação do requerimento (Processo 631/ 1968 - CFE).

Existiam ainda aqueles que, aproveitando o momento, pegavam a chance de ampliar o seu quadro de alunos e buscar financiamento por meio do logro à legislação vigente. Esse era o caso dos estudantes que conseguiam se matricular em escolas superiores sem a certificação dos exames de madureza. Isto é, algumas escolas admitiam candidatos ainda não habilitados, fazendo o aproveitamento de suas matrículas após a apresentação da documentação requerida e agiam de forma irregular, já que admitiam alunos que ainda não tinham cumprido a etapa escolar anterior. O CFE advertia essas instituições, mas admitia o aproveitamento da matrícula daqueles que prestassem os exames de madureza com "pequena diferença de data" entre os casos. Tais candidatos eram aceitos tão logo comprovassem a mudança de nível (Parecer no 892 de 18/12/1968).

Portanto, motivadas pelos problemas de entrave educacional, grande fluxo de estudantes para as universidades, falta de vagas, distribuição de financiamento etc., aconteceram discussões à busca de novas reordenações do transcurso escolar, pensando em uma distribuição de pessoas que não acarretasse percepções 
muito visíveis de uma crise educacional resultante da falta de planejamento para com o crescimento demográfico escolar.

Os vestibulares passaram a ter destaque nessa discussão sobre as formas de admissão ao ensino superior, e a modificação de sua configuração, por si só, pode ser objeto de estudo histórico, já que evidencia a modificação dos critérios de seleção de pessoas, a partir de uma alteração daquilo que se compreendia por "avaliação". Anteriormente, os vestibulares eram feitos na forma de exames. Posteriormente, passaram a concursos. Essa alteração, para além de uma questão meramente semântica, tinha a seguinte proposição: a princípio, na entrada do curso superior, o candidato era ordenado por notas e conceitos (exames), segundo o seu desempenho. A sua avaliação era medida por suficiência. Com o vestibular na forma de concurso, buscava-se a aptidão intelectual para os cursos superiores e o desempenho do pleiteante se tornaria classificatório. Essa condição foi demarcada no Decreto-Lei no 464, de 11/02/1969 a partir do direcionamento dos artigos $4^{\circ}$ e $5^{\circ}$. Por meio do Decreto, a entrada de alunos em universidades passava à condição de concorrência unificada, com o caráter monetário, já que seria intermediado por agências terceirizadas para esse fim. Caso houvesse a aprovação, os alunos passariam por um primeiro ciclo que tinha a função, entre outras coisas, de filtrá-los pelas "insuficiências evidenciadas pelo concurso vestibular"15.

Em outras palavras, ao transformar o vestibular em um concurso, ficou estabelecido que o número de candidatos aprovados seria o equivalente ao número de vagas universitárias disponíveis, o que, politicamente, dava fim à visibilidade de uma multidão pleiteando vagas. Receberia a vantagem o aluno que se destacasse por efeito da competição, da forma como disposto no Decreto $\mathrm{n}^{\circ}$ 68.908, de 13 de julho de 1971, em seu artigo $2^{\circ}$ : "O Concurso vestibular far-se-á rigorosamente pelo processo classificatório, com o aproveitamento dos candidatos até o limite das vagas fixadas no edital, excluindo-se o candidato com resultado nulo em qualquer das provas". O fato de se ter mudado o formato do vestibular não solucionou a falta de vagas nos cursos superiores, mas fez desaparecer o fenômeno dos excedentes, índice que definia de forma muito evidente o desamparo de um grande contingente de jovens que viam na escolarização uma possibilidade de trajetória de vida.

Mesmo diante das discussões e soluções apresentadas, tempos mais tarde foi anunciada a lacônica preocupação do Ministério da Educação com os estudantes brasileiros que recorriam às universidades estrangeiras, após a tentativa

15 A seleção de alunos feita por concurso vestibular, entretanto, já estava apresentada na Lei $n^{\circ} 5.540$, de 28 de novembro de 1968 , que fixou as normas de organização e funcionamento do ensino superior e a sua articulação com a escola média, a Lei da Reforma Universitária. 
frustrada de fazer o curso no seu país. De acordo com o artigo, os alunos saíam do Brasil "decepcionados" e voltavam ao país "humilhados", por conta das hostilidades que sofriam (EBSA, 1974, p. 64).

\section{Considerações finais}

Segundo Martins (2009, p. 19), a sociedade brasileira passava, desde os anos 1950, por um processo de concentração de propriedade e renda que, acentuado pela política econômica adotada a partir de 1964, acabou por conduzir as classes médias para o ensino superior, encarando-o como uma estratégia para a concretização de seu projeto de ascensão social. Essa modificação na "fisionomia social" teria transformado a universidade em uma instituição "mais próxima" do estudante.

Aumentar o número de vagas passou a ser a matéria corrente no discurso de professores, técnicos, burocratas e reformadores. Dentro de uma história dos excedentes, percebeu-se que o "problema" apresentava uma realidade de várias ordens: de plano físico-estrutural das escolas, administração governamental, distribuição de recursos, organização e planejamento curricular aos métodos de ensino; tinha relação com o comportamento dos alunos e ao seu histórico escolar; ao plano de trabalho e horas dos professores etc.

$\mathrm{O}$ caso dos excedentes deixa à mostra um problema de ordem educacional que acabou travando as trajetórias de vida de jovens que enxergaram o ensino superior como uma etapa subsequente do seu histórico escolar. No período, percentualmente, o volume de jovens que se transferia de um nível escolar para outro era pequeno. No entanto, foi um número suficientemente grande para dar visibilidade à falta de estrutura da Universidade para recebê-los.

Num primeiro momento, no início dos anos 1960, encontramos os excedentes, individualmente, usando mandados de segurança para garantir as suas vagas, impetrados pelas possíveis interpretações da Lei. Depois, ao final da década, advogava-se a necessidade de formação de profissionais técnicos de nível superior a partir de uma reorientação do mercado profissional, o que redimensionou a procura por cursos técnicos e de curta duração. Esse fato acabou lotando o CFE com pedidos de ampliação de vagas para alunos excedentes feitos pelas universidades e faculdades isoladas.

Pela hipótese de Cunha (2007, p. 24) a Reforma Universitária brasileira, muito mais do que uma imposição da tecnocracia militar em associação ao United States Agency for International Development (USAID), foi, antes de tudo, 
uma aspiração de vários setores da sociedade - administradores educacionais, professores e estudantes - que enxergavam a possibilidade de democratização do ensino superior. Essa ideia de democratização passava pelo fim do sistema de cátedras, considerado fechado, ultrapassado diante da representação de modernidade desenvolvimentista; corrupto, por conta de seu aparato selecionador sustentado no mérito acadêmico, mas também no clientelismo. Mas o sentido de "improvisação" do sistema de ensino, expressado ao longo desse estudo, reforçou a revolta dos estudantes, de forma a evidenciar os entraves objetivos que refreavam os caminhos para as Academias. Se houve uma movimentação próxima à democracia na história dos excedentes, ela estava reservada à própria ação juvenil, que deixou clara a carência do ensino superior para absorvê-los, dentro daquilo que se promovia como caminho aceitável rumo à autonomia social.

Havia tanto a preocupação sobre a organização dos estudantes, horizontalmente, ou seja, na sua distribuição em faculdades que tivessem como captá-los, quanto uma inquietação com a trajetória vertical do aluno, ao longo da seriação escolar, pois se evitavam as retenções de estudantes ao longo das séries de modo que a passagem às coortes subsequentes fosse desobstruída. Nos casos apresentados interessava a condução mais acelerada de alunos para a próxima etapa de escolarização dada a aglomeração populacional que era sentida, também, no ensino secundário brasileiro. Essa aceleração, associada às leis que, progressivamente, admitiram estudantes de todos os ramos do ensino médio no ensino superior, teria resultado na aglomeração de candidatos às portas da universidade. Por um lado, esse item da Lei de Diretrizes e Bases (LDB) de 1961 demonstrava a diluição do prestígio do ensino secundário como formador de uma elite educacional dirigente, mas, também, ampliou o acesso aos postos universitários, dados aos alunos dos vários segmentos do ensino médio, jogando a responsabilidade da acolhida de todos para as Universidades.

Entre os dois níveis de ensino foi construída uma barragem por meio de dois processos educacionais diferentes, que juntos criaram uma zona de estrangulamento no sistema de ensino. O primeiro, acontecido durante o ensino médio, empurrava os alunos para frente, já que o debate social quanto à aprovação ou reprovação dos jovens no histórico do ensino médio nos deu indícios sobre esse processo de aceleração do fluxo escolar. O segundo condicionou o bloqueio dos jovens às portas da universidade, por conta da somatória de uma série de problemas: falta de vagas; o preconceito explícito pela "invasão" da massa estudantil, empecilhos das mais variadas matizes: espaciais, administrativos, acadêmicos etc.

A falta de vagas associada ao desaparelhamento dos cursos superiores dinamizaram os manifestos estudantis de rua que, em contrapartida, com ampla exploração jornalística, eram cada vez mais associados à infiltração comunista 
no Brasil, dando chance aos conhecidos movimentos de repressão política. O movimento estudantil, inclusive, foi usado como pretexto para a abertura de novas instituições ou modificações no formato dos cursos, pois havia quem buscasse transferir o potencial revolucionário dos jovens para atividades socialmente mais aceitas, como era o caso do trabalho e do estudo (BRAGHINI, 2010). Estudantes sofreram os danos oriundos de problema jurídico e estrutural. As disposições previstas pela Lei, que eram as garantias de prosseguimento dos estudos em ambientes aparelhados para tal fim, não foram de todo atendidas e houve reação diante da situação de desorganização e desamparo que esse entrave produziu. Aconteceram manifestações históricas que foram absorvidas por uma parcela da imprensa conservadora como subversão pura e simples.

No momento crucial de determinação de carreiras, houve um choque de absorção entre os dois níveis de ensino e foram pensados e planejados procedimentos para que houvesse, por um lado, a barragem do fluxo volumoso de jovens para o nível superior; por outro, assistimos a montagem de planos que visavam à distribuição de pessoas em dois planos diferentes: o primeiro, ao longo do segmento de nível médio, pensado como fase final da vida escolar; o segundo, dentro das universidades, por meio de cursos rápidos. Por outro lado, de forma tênue, mas violenta, alguns processos universitários seriam capazes de eliminar o excesso de alunos por meio do discurso da competência individual.

A escassez de recursos financeiros deu margem para discursos em defesa da escola pública, contrários ao escoamento do dinheiro estatal no sentido de abertura, manutenção ou federalização de escolas isoladas. Mas essa mesma escassez, agregada à revolta de estudantes, possibilitou a criação de um discurso que pedia por uma associação, entre a rede privada e a rede pública, no sentido de complementaridade, visando à ampliação do sistema. A Constituição de 1967, que cedeu recursos financeiros e expandiu a colaboração técnica para o ensino particular, foi o documento que marcou, historicamente, acordos políticos de outra natureza entre o Governo e o setor privado da educação, sob o pretexto de acréscimo de vagas.

Pensando na modificação do ensino médio, vemos a inserção dos jovens no mundo do trabalho como mote dos discursos. Não por coincidência a Lei $\mathrm{n}^{\mathrm{o}}$ 5.692 (11 de agosto de 1971) passou a considerar que no ensino de $2^{\circ}$ grau (antigo ensino médio) predominaria uma formação voltada para a habilitação ao trabalho, este também em consonância com os interesses profissionais regionalizados. As diversas críticas feitas a essa lei na historiografia miraram a sua condição "tecnicista", detalhando o empobrecimento teórico no qual foi jogado o ensino de nível médio no Brasil. Mas essa lei parece destacar que o ensino profissionalizante de nível médio, além de ter sido utilitário aos interesses de formação imediata de quadros técnicos para postos de trabalhos emergenciais, buscava 
escoar os estudantes para fora da escola rapidamente, na tentativa de impedi-los de dar seguimento de carreira e de vida por meio do caminho universitário.

A Lei no 5.692 aparece como um dispositivo, definidor de um processo que buscava resguardar a universidade, ápice da "pirâmide selecionadora", da incursão de alunos despejados pelo ensino médio brasileiro. Mais do que apresentar as formas de melhor distribuir, ou até mesmo impedir a entrada dos alunos nas universidades, houve quem apresentasse a "irrupção das massas de assaltantes legítimos" como algo que não deveria surpreender a Universidade.

Não podemos nos esquecer de que nem todos os jovens eram estudantes. Mas dentre estes, não deixa de ser sintomático o fato de que, naquele mesmo período, mais precisamente a partir de 1968, surgissem novas possibilidades de direções em suas biografias: a marcha estudantil, principalmente secundarista, rumo à luta armada, em batalha contra a ditadura; a apresentação de formas "alternativas" de vida dentro do que se convencionou chamar de "contracultura", pensando, por exemplo, no movimento hippie. Nos anos 1960, as formas "oficiais" de trajetória de vida escolar dos jovens tinham bloqueios e demandas categóricas e formaram um quadro histórico muito marcante.

\section{REFERÊNCIAS}

BOURDIEU, Pierre; PASSERON, Jean-Claude. Les héritiers: Les étudiants et la culture. Paris: Minuit, 1964.

BRAGHINI, Katya. A "Vanguarda Brasileira": A juventude no discurso da Revista da Editora do Brasil S/A (1961-1980). Tese (Doutorado em Educação: História, Política, Sociedade) - Pontifícia Universidade Católica de São Paulo, São Paulo, 2010.

BRASIL. Lei n ${ }^{\circ}$ 4.024, de 20 de dezembro de 1961. Fixa as Diretrizes e Bases da Educação Nacional. Diário Oficial da União, Brasília, DF, 27 dez. 1961. Disponível em: <http:// www.planalto.gov.br/ccivil_03/leis/14024.htm>. Acesso em: 01/02/2007.

. Lei $n^{0} 5.540$, de 28 de novembro de 1968. Fixa normas de organização e funcionamento do ensino superior e sua articulação com a escola média, e dá outras providências. Diário Oficial da União, Brasília, DF, 28 nov. 1968. Disponível em: <http://www. planalto.gov.br/ccivil_03/leis/15540.htm>. Acesso em: 28/06/2008.

Decreto $\mathrm{n}^{\circ}$ 68.908, de 13 de julho de 1971. Dispõe sobre Concurso Vestibular para admissão aos cursos superiores de graduação. Diário Oficial da União, Brasília, DF, 14 jul. 1971. Disponível em: <http://www.planalto.gov.br/ccivil_03/decreto/1970-1979/ D68908.htm>. Acesso em: 03/06/2009. 
. Lei $\mathrm{n}^{\circ} 5.692$, de 11 de agosto de 1971 . Fixa as Diretrizes e Bases de $1^{\circ}$ e $2^{\circ}$ graus, e dá outras providências. Diário Oficial da União, Brasília, DF, 12 ago. 1971. Disponível em: <http://www2.camara.leg.br/legin/fed/lei/1970-1979/lei-5692-11-agosto-1971-357752-publicacaooriginal-1-pl.html $>$. Acesso em: 24/02/2014.

Ministério da Educação e Cultura. Sinopse Estatística do Ensino Superior. Brasília, DF, 1965. p. 6-7.

CARVALHO, Jair Dias. Exames de segunda época. Revista da Editora do Brasil S/A, São Paulo, n. 179, p. 50-51, fev. 1963.

CHAGAS, Valnir. A luta pela Universidade no Brasil. Revista Brasileira de Estudos Pedagógicos, Rio de Janeiro, v. 48, n. 107, p. 44-59, jul./set. 1967.

. Continuidade e terminalidade do processo de escolarização. Revista Brasileira de Estudos Pedagógicos, Rio de Janeiro, v. 49, n. 110, p. 247-266, abr./jun. 1968.

CONSELHO FEDERAL DE EDUCAÇÃO (CFE). Faculdade de Direito de Guarulhos (SP). Aumento do número de vagas. Parecer no 343/68, aprovado em 05/06/1968. Processo 574/68 - CFE.

. Faculdade de Medicina de Itajubá. Autorização para a matrícula de 100 alunos. Parecer no 364/68, aprovado em 06/06/1968. Proposta do Conselheiro Pe. José Vasconcelos, pelo indeferimento. Processo 570/68 - CFE.

. Faculdade de Direito do Distrito Federal (DF). Aumento de matrícula. Parecer $\mathrm{n}^{\circ}$ 368/68, aprovado em 6/06/1968. Contra os votos dos Conselheiros Valnir Chagas, Moniz de Aragão e Ruben Maciel. Processo 631/68 - CFE.

. Faculdade de Direito de São Carlos. Matrícula de excedentes. Parecer n ${ }^{0}$ 588/68, aprovado em 03/10/1968. Processo 996/68 - CFE.

. Faculdade de Direito de Guarulhos (SP). Autorização de matrícula de 186 estudantes. Parecer $n^{\circ}$ 613/68, aprovado em 07/10/1968. Aprovado o voto em separado do Conselheiro Rubens Maciel. Processo 829/68 e 2000/68 - CFE.

. Situação de estudantes inscritos condicionalmente em exame vestibular. Parecer $\overline{\mathrm{n}^{\circ}} 892 / 68$, aprovado em 18/12/1968. Processo 1830/68 - CFE.

CUNHA, Luis Antônio. A universidade reformada - O golpe de 1964 e a modernização do ensino superior. São Paulo: Unesp, 2007.

DANTAS, Andréa Maria Lopes. Crônica de uma reforma anunciada: uma análise da seção Estudos e Debates da Revista Brasileira de estudos Pedagógicos nos anos 19611962 e 1972-1973. Dissertação (Mestrado em Educação: História, Política, Sociedade) - Pontifícia Universidade Católica de São Paulo, São Paulo, 1997.

EDITORA DO BRASIL. Cegos e delirantes. Revista da Editora do Brasil S/A, São Paulo, n. 163, p. 1-2, jun. 1962. 
A greve dos estudantes. Revista da Editora do Brasil S/A, São Paulo, n. 171, p. 43-45, jun. 1962 .

Gratuidade desarrazoada. Revista da Editora do Brasil S/A, São Paulo, n. 178, p. 35-36, jan. 1963 .

. Res, non verba. Triplicou em 2 anos o número de alunos dos cursos secundários oficiais do Estado da Guanabara. Revista da Editora do Brasil S/A, São Paulo, n. 179, p. 36-37, jun. 1963.

. Exames de Segunda época. Revista da Editora do Brasil S/A, São Paulo, n. 179, p. 50-51, jun. 1963.

Fracassou o "Ano da Educação" dada a incapacidade de seus realizadores: saldo negativo. Revista da Editora do Brasil S/A, São Paulo, n. 189, p. 48-61, dez. 1963.

Privilégios na Educação. Revista da Editora do Brasil S/A, São Paulo, n. 196, p. 68 , set. 1964 .

. Problemas de estudantes. Revista da Editora do Brasil S/A, São Paulo, n. 310, p. 64-65, jan. 1974.

FÁVERO, Maria de Lourdes de A. Universidade no Brasil: das origens à reforma universitária de 1968. Educar em Revista, Curitiba, n. 28, p. 17-36, 1972.

FORACCHI, Marialice M. A Juventude na Sociedade Moderna. São Paulo: Pioneira, 1971.

FREITAG, Bárbara. Escola, Estado e sociedade. São Paulo: Editora Moraes, 1986.

GOMES, Alfredo. Reformas e Reforma. Revista da Editora do Brasil S/A, São Paulo, n. 243, p. 1-4, jun. 1968.

JUDT, Tony. O Espectro da Revolução. Revista Piauí, São Paulo, n. 8, p. 48-54, 2007.

MARTINS, Carlos Benedito. A reforma universitária de 1968 e a abertura para o ensino superior privado no Brasil. Educação \& Sociedade, Campinas, v. 30, n. 106, p. 15-35, jan./abr. 2009.

MATHIAS, Suzeley Kalil. A militarização da burocracia: a participação militar na administração federal das comunicações e da educação, 1963-1990. São Paulo: Unesp, 2004.

NUNES, Clarice. A Modernização do ginásio e a manutenção da ordem. Dissertação (Mestrado em Educação) - Departamento de Filosofia da Educação, Instituto de Estudos Avançados em Educação, Fundação Getúlio Vargas, Rio de Janeiro, 1979.

REALIDADE. A juventude brasileira hoje - Edição Especial. São Paulo: Abril, set. 1967. p. 19-26.

RIBEIRO, Carlos Flexa. A educação em falência é fonte de crise política. Jornal do Brasil, Rio de Janeiro, Caderno Especial, p. 2, 5 mar. 1967. 
BRAGHINI, K. M. Z. A história dos estudantes “excedentes” nos anos 1960: a superlotação...

TRIGUEIRO, Durmeval. O problema dos excedentes e a Reforma Universitária. Revista Brasileira de Estudos Pedagógicos, Rio de Janeiro, v. 48, n. 107, p. 163-168, jul./set. 1967.

VALLE, Maria Ribeiro do. 1968: O Diálogo é a Violência - Movimento estudantil e ditadura militar no Brasil. Campinas: Unicamp, 1999.

Texto recebido em 20 de janeiro de 2014. Texto aprovado em 08 de fevereiro de 2014. 